\title{
Local Effect of Intranasal Beclomethasone Dipropionate Aerosol in Hay Fever
}

\author{
NIELS MYGIND
}

British Medical fournal, 1973, 4, 464-466

hay fever and to investigate the effect on the adrenal function when the drug is applied in the nasal cavity and partly absorbed from the mucous membrane of the upper respiratory tract.

\section{Summary}

The effect of a daily dose of $400 \mu \mathrm{g}$ beclomethasone dipropionate aerosol intranasally has been investigated in a double-blind cross-over trial in 29 patients with hay fever. The effect on the nasal symptoms was so pronounced in 25 patients that further symptomatic treatment was unnecessary. Beclomethasone dipropionate aerosol had, on the other hand, no direct effect on itching in the eyes, which is in accordance with the fact that biochemical investigations did not show any sign of suppression of the adrenal function. It is concluded that beclomethasone dipropionate aerosol intranasally is an effective and apparently harmless way of controlling the nasal symptoms in hay fever.

\section{Introduction}

Several attempts have been made to treat allergic rhinitis by intranasal application of corticosteroids in order to obviate the suppression of adrenal function caused by systemic therapy, and thereby avoid the unpleasant side effects of the steroids. Some authors have found intranasal applications of hydrocortisone and prednisone effective in the treatment of hay fever, but the symptomatic improvement has not been so convincing that these preparations have gained widespread use in therapy (Foulds et al., 1955; Godfrey et al., 1957; Uhde, 1957). Intranasal dexamethasone phosphate in a dose of $1 \mathrm{mg}$ daily gives an appreciable improvement of hay fever symptoms in about $75 \%$ of patients (Norman and Winkenwerder, 1965). However, this dose also gives nearly a $50 \%$ reduction of 17 -ketogenic steroid excretion at the end of one week's use (Norman et al., 1967). This form of treatment has little or no advantage over systemic steroid.

Beclomethasone dipropionate is a synthetic steroid with a powerful topical action. Encouraging results have now been reported from several authors using this drug as a pressurized aerosol in asthmatic patients. These reports suggest that the drug is effective in a daily dose of $400 \mu \mathrm{g}$ without evidence of adrenal suppression (Brown et al., 1972; Lal et al., 1972; Gaddie et al., 1973; Maberly et al., 1973). The reports concerning the suppressive effect of $400 \mu \mathrm{g}$ daily in healthy volunteers are, however, more conflicting. Harris et al. (1973) found no evidence of adrenal suppression of beclomethasone dipropionate aerosol in doses of $1 \mathrm{mg}$ and less, while Mygind and Hansen (1973) found a reduction of 17-ketogenic steroid excretion of about $50 \%$ with $800 \mu \mathrm{g}$ a day, and even with $400 \mu \mathrm{g}$ this investigation indicated a slight effect on the adrenals.

The present study was undertaken to assess the possible efficacy of intranasal beclomethasone dipropionate aerosol in

\footnotetext{
Otopathological Laboratory and Medical Outpatients' Clinic, Division for Allergic Diseases, Rigshospitalet, Blegdamsvej 9, 2100 Copenhagen, Denmark

NIELS MYGIND, M.D., Research Fellow
}

\section{Patients and Methods}

Thirty-three patients with hay fever symptoms for more than two seasons and with skin tests positive for grass pollen extract were studied. No regard was taken as to whether they were hyposensitized preseasonally or not; this was, however, the case for 15 persons. The decisive principle was whether they had sufficiently pronounced symptoms to be able to evaluate the effect of the drug. Three patients were withdrawn from the trial because they had only minor symptoms from the nose as well as from the eyes. One more patient was withdrawn as he failed to appear at the control stage. Of the 29 patients who completed the trial nine were females and 20 males. Their mean age was 25 years (range 14-36) and the average duration of the symptoms was 11 seasons (range 3-20).

The aerosol used was the same as is used for asthma, but equipped with a special nasal adaptor made at this hospital. It delivers $50 \mu \mathrm{g}$ per puff, and the dose was one puff into each nostril four times daily-that is, a daily dose of $400 \mu \mathrm{g}$.

Patients were allocated at random to two groups. The first group (17 patients) was given beclomethasone dipropionate aerosol for two weeks, followed by an identical placebo aerosol for a further two weeks, while the second group (12 patients) received the treatment in the reverse order. The trial was started on 11 June-that is, about one week after the onset of hay fever symptoms in most patients. Besides the aerosol the patients were supplied with antihistamine tablets, dexchlorpheniramine maleate (Polaramine), to be taken ad libitum if the effect of the aerosol was unsatisfactory. Furthermore, they were given eye-drops, antazoline hydrochloride (Antistin-Privine), to be used instead of antihistamine tablets for eye symptoms. Every use of drugs was recorded, and the patients filled in diary cards daily, where the symptoms nasal blocking, secretion, sneezing, and eye itching were evaluated semi-quantitatively according to a scale from 0 to 3 . In no case was the code broken before the patient had reported his preference and the result of the trial was evaluated.

In 12 males 17-ketogenic steroids were estimated in urine (as described by Few (1961)) at the end of the first and at the end

Urinary Excretion of 17-Ketogenic Steroids in 12 Males at End of Treatment Periods

\begin{tabular}{c|c|c}
\hline Case No. & $\begin{array}{c}\text { Placebo } \\
\text { Aerosol } \\
(\mu \mathrm{mol} / 24 \mathrm{hr})\end{array}$ & $\begin{array}{c}\text { Beclomethasone } \\
\text { Dipropionate } \\
\text { Aerosol } \\
(\mu \mathrm{mol} / 24 \mathrm{hr})\end{array}$ \\
\hline 3 & 33 & 28 \\
8 & 37 & 42 \\
11 & 21 & 18 \\
14 & 21 & 35 \\
16 & 48 & 28 \\
20 & 34 & 36 \\
21 & 25 & 21 \\
26 & 33 & 38 \\
28 & 34 & 37 \\
30 & 34 & 18 \\
33 & 24 & $29 \cdot 1$ \\
\hline Mean & $31 \cdot 3$ & \\
\hline
\end{tabular}


of the second period of treatment (table). The urinary metabolites from beclomethasone dipropionate do not greatly affect urinary 17-ketogenic values. A $400 . \mu \mathrm{g}$ dose of beclomethasone dipropionate aerosol gives a maximal addition of $0.07 \mathrm{mg}$ to the 24-hour urine 17-ketogenic steroid value (Harris et al., 1973).

\section{Results}

The timing of the trial was found to be correct, as the intensity of the symptoms increased slightly in the first period and decreased somewhat in the second period. During the latter, however, the symptoms were less pronounced, thus favouring the drug order placebo-beclomethasone dipropionate. The meteorological conditions were exceptionally good, as both periods had warm and dry weather with sunshine.

Of the 29 patients studied 25 preferred the active aerosol, 2 preferred the placebo aerosol, and 2 had no preference. When the scores from the diary cards were compiled, they showed that the active aerosol had a pronounced effect both on blocking of the nose, secretion, and sneezing. The sum of all nasal scores per day in the two periods is shown in the graph. Owing to seasonal variations in the symptom intensity the drug order placebo-beclomethasone dipropionate shows a more significant result than the reverse order. It appears that there is a strong discrepancy between the pronounced effect on nasal symptoms and the very slight difference in eye scores when on the active aerosol compared with the placebo treatment. The patients reported no effect of beclomethasone dipropionate aerosol on eye symptoms, and the small difference in the two periods is most easily explained as a transmitted influence from the nose on the eye symptoms. There was no significant difference in the use of eye-drops in the two periods. In the last week of treatment the group on the placebo used 195 eye-drops and patients on the active aerosol used 182 drops. In a few cases the active aerosol perhaps had an indirect effect on the eye symptoms, as two patients in the active drug period complained of pronounced eye symptoms after a few days which they had not experienced before. Both patients had such good results from the active aerosol on the nasal symptoms that contrary to previous years they entirely omitted the use of antihistamine tablets and to a higher degree than previously exposed themselves to grass pollen. Because of the latter fact it is possible that asthma symptoms might become worse during intranasal treatment with beclomethasone dipropionate aerosol. However, we have not been able to confirm this supposition, as the patients in this trial did not suffer from asthma, and no case of asthma started during the trial.

Altogether, the placebo group took 214 antihistamine tablets during the last week of treatment whereas the active aerosol group took only 26 . In 25 of the 29 patients the effect of the active aerosol was so pronounced that they used only two antihistamine tablets in total, while 203 tablets were taken during the last week of placebo treatment.

Beclomethasone dipropionate aerosol did not act immediately, but had a significant effect on the second day (see graph). During the next three to five days the symptoms diminished somewhat. The active preparation was effective one to two days after it had been discontinued. This sustained effect also caused the patients not to have the usual sneezing attack early in the morning.

While the patients reported no effect of the active aerosol on eye itching, some felt relief on itching in the throat. Sixteen patients found that use of the aerosol gave rise to a few sneezes, especially in the placebo treatment. None stopped using the aerosol owing to side effects. This was controlled by assessing the number of doses left in the aerosol. Only one patient reported more than negligible direct inconvenience when using the aerosol. It may therefore be concluded that this form of beclomethasone dipropionate administration was very well tolerated.

The mean value of 17 -ketogenic steroids in urine was $7 \%$ lower in the active drug period than in the period of placebo

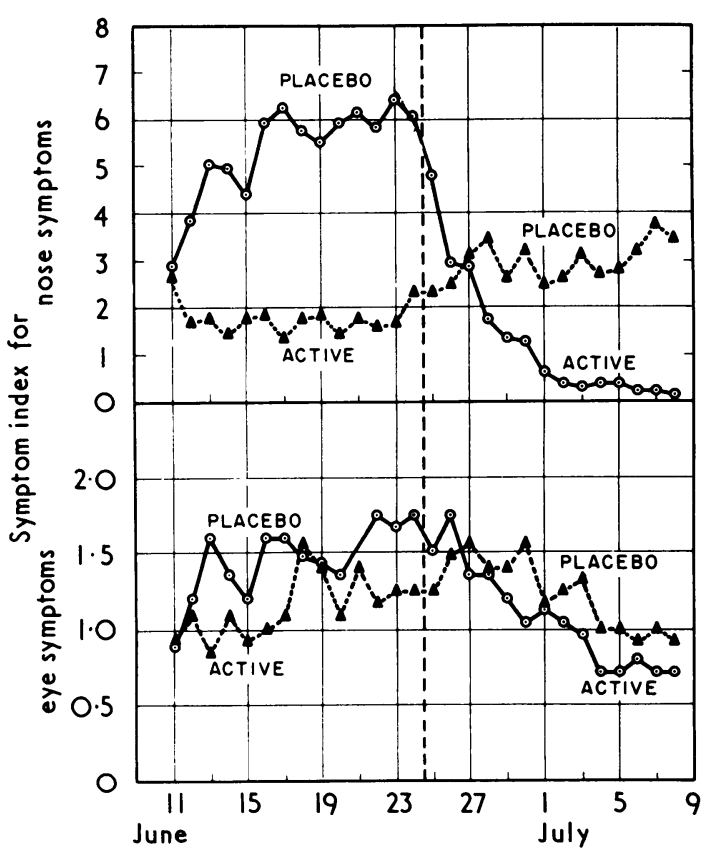

Average daily symptom scores of hay fever from 29 diary cards.

treatment. This difference was, however, not significant, and there was no noticeable effect on the adrenal function of a daily active dose of $400 \mu \mathrm{g}$ intranasally for two weeks.

\section{Discussion}

It is remarkable that with only a local effect of a corticosteroid it is possible to make other symptomatic treatment of nasal symptoms superfluous in $85 \%$ (95\% security limits: $68-96 \%$ ) of patients with hay fever. This effect exceeds what has been obtained previously with dexamethasone phosphate intranasally (Norman and Winkenwerder, 1965) and depot steroids (Ganderton et al., 1969). While these two drugs always give varying degrees of adrenal suppression, this is apparently not the case with beclomethasone dipropionate aerosol intranasally. The indications that there is no systemic action are firstly that it was not possible to show any significant change in the urinary excretion of 17-ketogenic steroids before and after treatment, and secondly that there was a pronounced discrepancy between the effect of the active aerosol on nasal symptoms and the lack of direct effect on eye symptoms. This is opposite to the effect obtained by intranasal application of $1 \mathrm{mg}$ dexamethasone phosphate, where nasal as well as eye symptoms were alleviated in nearly the same degree (Norman and Winkenwerder, 1965).

The results of the present study taken together with the last few years' experience with beclomethasone dipropionate aerosol in the treatment of asthma suggest that $400 \mu \mathrm{g}$ of the drug given intranasally is an apparently harmless and effective treatment of nasal symptoms in hay fever. If eye-drops are given at the same time it is possible that only a local symptomatic treatment will be needed in most cases. In this way both the sedative effect of antihistamines and the systemic effects of depot steroids can be avoided.

We wish to thank Glaxo, Copenhagen, for supply of the aerosols, and Mr. Osvald Nielsen, Rigshospitalet, for making the nasal adaptors used in this study.

\section{References}

Brown, H. M., Storey, G., and George, W. H. S. (1972). British Medical Fournal, 1, 585. 
Few, J. D. (1961). Fournal of Endocrinology, 22, 31

Foulds, W. S., Greaves, D. P., Herxheimer, H., Kingdom, L. G., and Camp, M. B. (1955). Lancet, 1, 234.

Gaddie, J., et al. (1973). Lancet, 1, 691

Ganderton, M. A., Brostoff, J., and Frankland, A. W. (1969). British Medical fournal, 1, 357.

Godfrey, M. P., Maunsell, K., and Pearson, R. S. B. (1957). Lancet, 1, 767

Harris, D. M., Martin, L. E., Harrison, C., and Jack, D. (1973). Clinical Allergy. In press.
Lal, S., Harris, D. M., Bhalla, K. K., Singhal, S. N., and Butler, A. G. (1972). British Medical fournal, 3, 314.

Maberly, D. J., Gibson, G. J., and Butler, A. G. (1973). British Medical fournal, 1, 778 .

Mygind, N., and Hansen, I. (1973). Acta Allergologica. In press.

Norman, P. S., and Winkenwerder, W. L. (1965). Journal of Allergy, 36, 284

Norman, P. S., Winkenwerder, W. L., Agbayani, B. F., and Migeon, C. J. (1967). Fournal of Allergy, 40, 57.

Uhde, H. (1957). Münchener Medizinische Wochenschrift, 99, 891.

\section{MEDICAL MEMORANDA}

\section{Epidermal Necrolysis from Clothing Impregnated with Paraffin}

\author{
R. L. BARNES, D. S. WILKINSON
}

British Medical fournal, 1973, 4, 466-467

Toxic epidermal necrolysis was first described by Lyell (1956) in Great Britain and Lang and Walker (1956) in South Africa. The explosive nature of the eruption, which often occurs in young subjects, and the characteristic "sliding away" of the epidermis over a red and sharply demarcated base usually allow easy recognition.

In a review of 128 cases Lyell (1967) found staphylococci (particularly of phage type 71 ) and drugs responsible for just over half the cases in children under 10 years of age. Drugs were responsible for most cases in early adult life. In his "miscellaneous" group-occurring at all ages-he mentioned "poisons" as a cause in five cases. One of these was due to externally encountered paraffin (kerosene) in an epileptic. The following case history draws attention to this cause of an acute necrolytic eruption which may occur more often than is apparent from the sparse records.

\section{Case History}

A 12-year-old boy was brought to the casualty department of Wycombe General Hospital on a Sunday morning in February 1972, having developed a rash of rather startling appearance on the second day of a camping weekend. The eruption was characteristically that of toxic epidermal necrolysis and he was admitted to the dermatology ward. On examination he was found to be a cheerful and obviously healthy boy. Temperature and pulse rate were normal and his only complaint was of pain, discomfort, and limitation of movement associated with the eruption. This consisted of an extensive area of intensely erythematous skin over which the epidermis had either become detached or could be detached by slight movement of the fingers. At the lower level of epidermal loosening there was a collection of apparently purulent fluid. The eruption, involving an area of about $150 \mathrm{~cm}^{2}$, extended upwards on each side of the chest to include the axillary folds and the inner aspects of the upper arms as far as the antecubital fossae. The axillary apices were spared. Two smaller patches were present on the front of the neck. There were no mucosal lesions and the rest of the skin was clear.

Wycombe General Hospital, High Wycombe, Bucks

R. L. BARNES, III, M.D. (Present position: Pediatric Resident, University of Alabama Medical Center, U.S.A.)*

D. S. WILKINSON, M.D., F.R.C.P., Consultant Dermatologist

* Dr. Barnes made the diagnosis of this case while spending his elected period at Wycombe General Hospital as a medical student.
Progress was uneventful with bland treatment and he was discharged a week later. A nasal swab grew Staphylococcus aureus, phage type 55. Swabs from the throat and the purulent skin sac were sterile.

On the day after admission a fuller history was obtained from his parents who confirmed the absence of any preceding illness, medicines, or drugs. The boy had left for a weekend camping expedition with other members of a club on the Friday night. The clothes he carried in his knapsack had been packed in a polyethylene bag, separate from other camping equipment, which included a plastic one-litre bottle containing paraffin (kerosene). The first day passed without incident and the boy noticed the rash only on waking on the Sunday morning. He had slept in pyjamas over which he wore a heavy sweater, the weather being somewhat cold. It is probable that he had not replaced his clothes in the polyethylene bag on the Saturday morning and it is certain that they came in contact with the paraffin because the smell was noticed strongly on his clothes by his parents when they unpacked his bags.

A plastic container similar to the type used by him was half filled with paraffin and subjected to only a light shaking associated with an upright position on a car journey. After some minutes it was apparent that paraffin was leaking out from the sides of the cap, even though this had been reasonably firmly screwed on.

\section{Comment}

Both petrol and paraffin (kerosene) are known to produce skin lesions exactly simulating those of toxic epidermal necrolysis, and such cases have, in fact, been included in accounts of this disease (Lyell, 1967, Merien et al., 1961, Walker, 1962). Kerosene fuel caused extensive lesions on the bodies recovered from the sea after the Comet aircraft disaster in 1954 (Armstrong et al., 1955). The lesions are usually confined to areas covered by clothing and have well-demarcated edges. A similar picture occurred in a boy of 3 years whose head had been immersed in a pool of petrol (Ainsworth, 1960), and Aidin (1958) described the same changes in another boy killed in a vat of petrol. Absorption of petrol vapour from petrol lighters in aircraft causing similar burns on the thigh was the subject of correspondence in this journal over 20 years ago.

The present case is noteworthy, as it occurred in circumstances which are likely to be encountered more often. The combination of a plastic type of container (which is not ideal for carrying volatile liquids) and failure to keep the container separated from clothing in the knapsack were the cause of contamination. The wearing of a heavy pullover on top of the pyjamas obviously enhanced prolonged contact with the skin. The pyjama trousers were not so covered and, as they had been rolled up on top, were probably less contaminated.

It is not difficult to envisage that this combination of circumstances might occur again. We feel that careful instructions should be given by club leaders and medical officers concerned with camping on the correct packing of paraffin and similar fluids.

As this is a true chemical "burn" we have thought it best to acknowledge the similarity with Lyell's syndrome but to stress ils separate identity by omission of the word "toxic", used by Lyell to describe the prodromal toxaemia occurring in his cases. 